\title{
Development of the Models to Estimate a Micro-structures in the Concrete of Nuclear Power Plant
}

\author{
Jong-Suk Lee, Ho-Jae Lee, Myungsug Cho, and Do-Gyeum Kim
}

\begin{abstract}
This study evaluated the change of micro structure caused by the deterioration factors in the structure of nuclear power plant out of concrete structure. Because the nuclear power plant is influenced more seriously than general structures when the deterioration phenomenon occurs, the deterioration of its concrete should be reevaluated by the viewpoint of micro structure rather than by the existing deterioration evaluation method.

Accordingly, this study estimated the diffusion behavior of toxic ion based on the mechanical properties such as concrete strength in order to develop an estimation model of time-based micro structure of the concrete used for nuclear power plants.
\end{abstract}

Index Terms-Nuclear power plant, concrete structure, deterioration, micro structure and mathematic model.

\section{INTRODUCTION}

Concrete structure's performance may be deteriorated a variety of deterioration factors such as chloride-included corrosion, freeze thaw, sulfate-caused erosion and carbonatization [1]. Especially, when the deterioration phenomenon occurs in a nuclear power plant, the durability and safety in the structure may be deteriorated and the structure soundness and leas resistance may be influenced seriously[2]-[4], so the result may lead to the more serious effect in the structure rather than general concrete structure. Some of those problems are now found at some nuclear power plants which are now been operated in Korea, but it lacks the general data and technology with regard to deterioration factors and phenomena. Accordingly this study purposes to analyze the concrete micro structure regarding deterioration factor so that the nuclear power plant can be managed systematically and scientifically.

Concrete has the mechanical properties including the strength established through hydration reaction according to the passage time of binding materials like cement [5]-[11]. Then, there are irregular voids among the produced hydrates,

Manuscript received January 28, 2013; revised March 29, 2013. This work was supported by the Nuclear Research \& Development of the Korea Institute of Energy Technology Evaluation and Planning (KETEP) grant funded by the Korea government Ministry of Knowledge Economy (No. 2011T100200161).

Jong-Suk Lee, Hojae Lee, and Do-Gyeum Kim are with the Structural Engineering Research Division, Korea Institute of Construction Technology, South Korea (tel.: +82-31-910-0139, +82-31-910-0390, +82-31-910-0133; fax: +82-31-910-0715; e-mail: jslee@kict.re.kr, h.lee@kict.re.kr, dgkim@kict.re.kr).

Myungsug Cho is with the Plant Construction \& Engineering Laboratory, KHNP Central Research Institute, Korea Hydro \& Nuclear Power Co., LTD, South Korea (tel.: +82-42-870-5824; fax: +82-42-870-5819; e-mail: concrete@khnp.co.kr). so the general void ratio is directly related to the penetration properties of toxic materials such as chloride ion as well as the mechanic properties such as the strength of concrete [12], [13]. Accordingly, the revelation behavior of concrete micro-void structure depending on the passage time change is required to quantify in order to estimate more exactly the phenomenon regarding the mechanism and durability of concrete [14]-[16].

\section{TEST}

This study created both a freeze thaw specimen and a sulfate one by using the mixture used at nuclear power plant structure. The used materials were ones used at the real nuclear power plant structure. When it comes to the deterioration conditions, the freeze thaw was repeated 6-8 times a day using an underwater thaw test after quick freezing on air out of the concrete resistance test methods for quick freeze thaw defined at KS F 2456, the elastodynamic coefficient and weight change were performed every 30 cycles and the change of void amount was measured by using a mercury-injection method after finishing 50 cycles, and when it comes to sulfate, over the specimen soaked into $5 \%$ $\mathrm{Na}_{2} \mathrm{SO}_{4}$, the change of weight and length for the soakage period of 28 and 56 days was measured and the hydrate products were measured using X-ray diffraction analyzer (See Table I).

TABLE I: MiXTURE DESIGN FOR ANALYZING THE Micro STRUCTURE

\begin{tabular}{lllllll}
\hline \hline Water & Cement & Fly ash & $\begin{array}{c}\text { Agg } \\
(3 / 4 ")\end{array}$ & Sand & WRA & AEA \\
\hline 0.4 & 0.8 & 0.2 & 2.31 & 1.84 & 0.004 & 0.0004 \\
\hline
\end{tabular}

In addition, the estimation model for micro-void structure contains a variety of assumptions in order to explain the complex relations when the real cement binding materials produces the hydrate reactions, so it cannot help showing some differences from the real concrete void ratio. Accordingly, in order to examine the program developed at this study, the void ratio was measured through MIP test at the age of 90 days in the concrete specimen manufactured as Table II and then the comparison and review with the program's estimated results was performed.

TABLE II: MiXTURE DESIGN FOR ANALYZING THE VOID OF MICRO STRUCTURE

\begin{tabular}{cccccccc}
\hline \hline \multirow{2}{*}{$\begin{array}{c}\text { fck } \\
(\mathrm{MPa})\end{array}$} & \multirow{2}{*}{$\begin{array}{c}\mathrm{Gmax} \\
(\mathrm{mm})\end{array}$} & $\mathrm{W} /(\mathrm{C}+\mathrm{P})$ & \multicolumn{5}{c}{ Unit $(\mathrm{Kg} / \mathrm{m} 3)$} \\
\cline { 4 - 8 } & $\%$ & $\mathrm{~W}$ & $\mathrm{C}$ & $\mathrm{Slag}$ & $\mathrm{S}$ & $\mathrm{G}$ \\
\hline 24 & 25 & 50 & 180 & 270 & 90 & 804 & 935 \\
\hline \hline
\end{tabular}




\section{ANALYSIS OF RESULTS}

\section{A. Analysis of Results}

The results of freeze thaw test were shown as Fig 1 and 2 . As the void distribution is shown at Fig 1, it can be known that the total void amount increased after 50 cycles. Accordingly, it can be known through the repeated process of freeze thaw that the void size existing within the specimen was increasing. In addition, Fig 2 showed the change of relative elastodynamics coefficient and mass: it can be known that according to the test results till 150 cycles, they are reduced slight without big difference. According to this test, the nuclear power structure is deteriorated by the freeze thaw, but it can be said the effect is remained very slight.

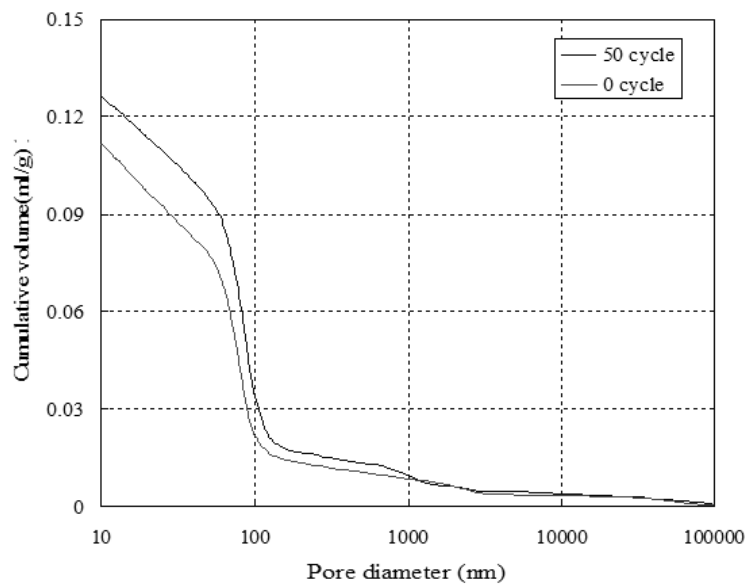

Fig. 1. Void Distribution

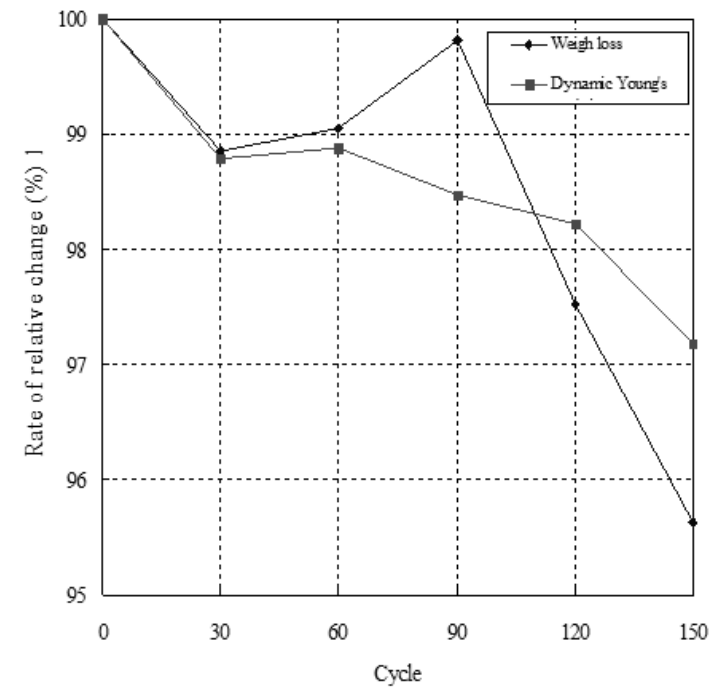

Fig. 2. The change of mass and that of the relative size of elastodynamics coefficient

\section{B. Analysis on Sulfate Results}

After soaking into $5 \% \mathrm{Na}_{2} \mathrm{SO}_{4}$ solution, the hydrate was checked through the change of length and mass and the XRD analysis as Fig 3 and 4. As shown at Fig 3, it can be known that the length and mass increased by around $0.3 \%$. It's found that they were expanded by the ettringite of initial hydrates, so the inner specimen was occurred airtight. And as shown at the result of XRD at Fig 4, it can be found that $\mathrm{Ca}(\mathrm{OH})_{2}$ and ettringite of hydrates were produced in the entire measurement sections. As seen at Equation (1), because $\mathrm{Ca}(\mathrm{OH})_{2}$ is vulnerable to sulfate ion, it produced ettringite: as a result, as the time passes, the crack produced by expansion is shown (Mehta et al., 2004). In this study, it's found that because the period of soakage was short in this study, the problems caused by $\mathrm{Ca}(\mathrm{OH})_{2}$ and sulfate ion reaction didn't occur.

$\mathrm{C}_{3} \mathrm{~A} \cdot \mathrm{CH} \cdot \mathrm{H}_{18}+2 \mathrm{CH}+3 \mathrm{~S}+11 \mathrm{H} \rightarrow \mathrm{C}_{3} \mathrm{~A} \cdot 3 \mathrm{CS} \cdot \mathrm{H}_{32}$
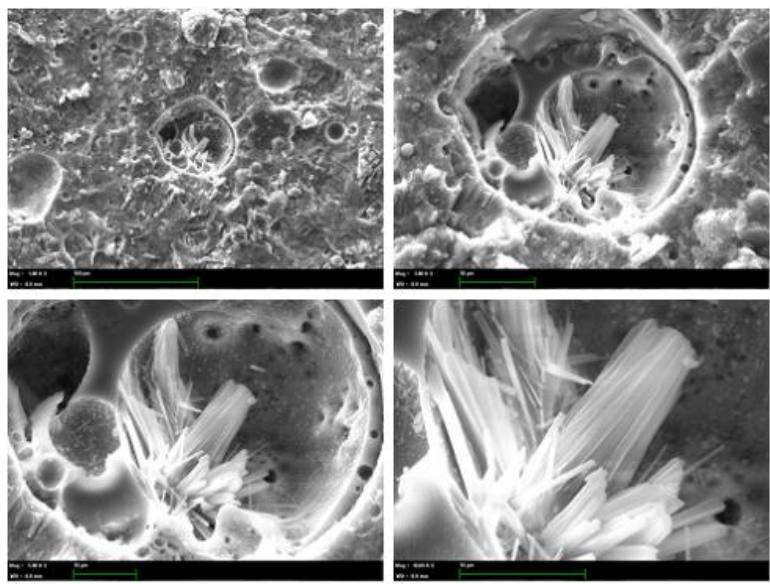

Fig. 3. Pictures of SEM analysis for sulfate test
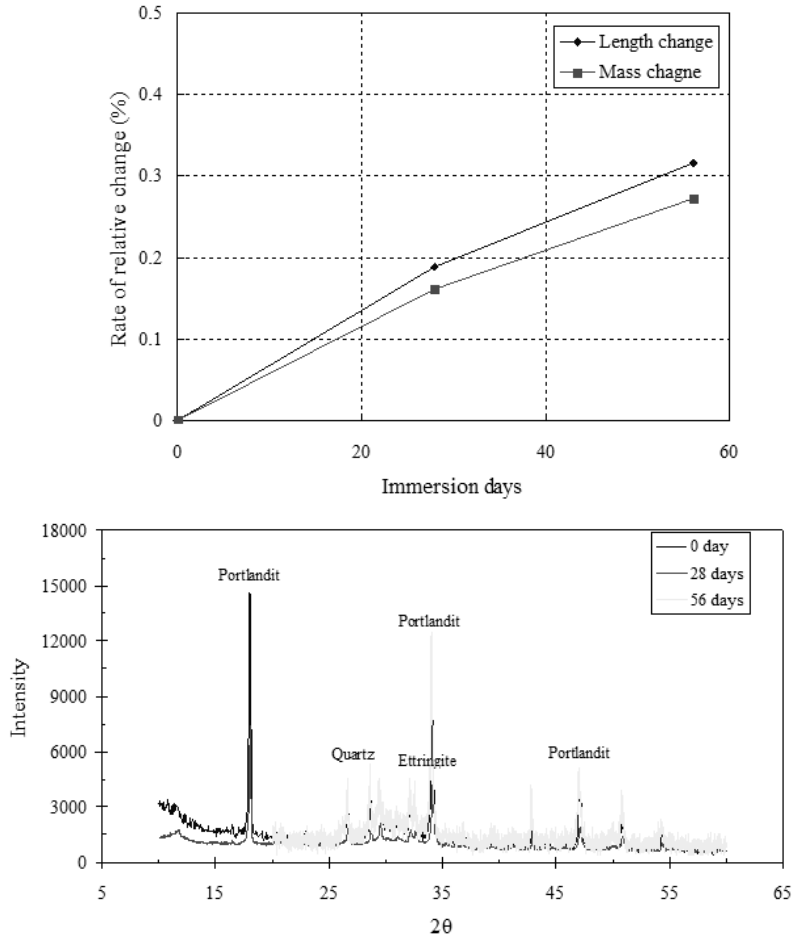

Fig. 4. Length change cause by sulfate and XRD analysis.

\section{FORMULARIZATION OF MICRO-VOID STRUCTURE}

When presenting a model forming the void structure, Chaube assumed that the cement paste is composed of powder particles with the averaged representative diameter ' $r_{0}$ ', and presented a formula to acquire the averaged interval ' $\mathrm{s}$ ' among powder particles with the ratio ' $\omega_{0}$ ' of moisture and powder, the powder fineness 'BF' and $\rho_{\mathrm{p}}$ the powder gravity.

$$
\begin{aligned}
& s=2 r_{0}\left[\left\{G_{0}\left(1+\rho_{p} \omega_{0}\right)\right\}^{1 / 3}-1\right] \\
& G_{0}=0.79(B F / 350)^{0.1} G_{0} \leq 0.91
\end{aligned}
$$

Meanwhile, for the convenience in terms of value interpretation, Chaube substituted cementation-available 
space to a cylinder with the radius of ' $r_{\mathrm{eq}}$ ' with the averaged interval among the particle centers.

$$
r_{e q}=\left(\frac{3}{4 \pi}\right)^{1 / 3} l=k l
$$

He composed the particle model as above, classified the voids produced at time of hydration as gel voids, capillary ones and interlayer ones and assumed that the void ratio retained by $\mathrm{C}-\mathrm{S}-\mathrm{H}$ gel particle is constant at 0.28 . In addition, he assumed that the gel voids and interlayer ones are included to hydrate particle while the capillary ones are the spaces where C-S-H gel particle or C-H crystal don't occupy. According to the above assumptions, the volume ${ }^{~} \mathrm{~V}_{\mathrm{S}}\left(\mathrm{m}^{3} / \mathrm{m}^{3}\right)$ ', of gel particle can be acquired through the averaged hydration degree ' $\alpha(0 \leq \alpha \leq 1)$ ' of the composition mineral of each cement and the combined amount ' $\beta\left(\mathrm{kg} / \mathrm{m}^{3}\right)$ per unit powder weight, and in this case, the hydration-related variables, namely the hydration degree ' $\alpha$ ' and combined amount ' $\beta$ ', can be identified through a complex hydration heat model of Kishi.

$$
V_{s}=\frac{\alpha W_{p}}{1-\phi_{c h}}\left(\frac{1}{\rho_{p}}+\frac{\beta}{\rho_{u}}\right)
$$

where,

$W_{p}$ : cement weight per unit volume $\left(\mathrm{kg} / \mathrm{m}^{3}\right)$

$\rho_{p}$ : powder density $\left(\mathrm{kg} / \mathrm{m}^{3}\right)$

$\rho_{u}$ : the gravity of water bound to hydrates after reaction $\left(1.25 \times 103 \mathrm{~kg} / \mathrm{m}^{3}\right)$

$\phi_{c h}$ : void ratio with gel properties -0.28

The void ratio of gel particle is composed of interlayer void and gel one, so the void ratio of interlayer void ' $\phi_{\mathrm{lr}}$ ' and that of gel void ' $\phi_{\mathrm{gl}}$ ' can be acquired as follow:

$$
\phi_{l r}=\left(t_{w} s_{l} \rho_{q}\right) / 2 \phi_{q l}=V_{s}\left(\phi_{c h}-\phi_{l r}\right)
$$

where $t_{w}$ refers to the thickness of interlayer void $(2.8 \AA), \mathrm{S}_{1}$ the unique surface area of interlayer void (in cased of Portland cement, $500 \sim 600 \mathrm{~m}^{2} / \mathrm{g}$ ) and $\rho_{\mathrm{q}}$ the dried density of gel products $=\rho_{p} \rho_{w}(1+\beta)\left(1-\phi_{c h}\right) /\left(\rho_{w}+\beta \rho_{p}\right)\left(\mathrm{kg} / \mathrm{m}^{3}\right)$ and the more detailed contents are omitted in this page.

Finally, the void ratio of capillary void ' $\phi_{\mathrm{cp}}$ ' is as follow:

$$
\phi_{c p}=1-V_{s}-(1-\alpha)\left(W_{p} / \rho_{p}\right)
$$

In the Multi-component model developed by Kishi etc., the whole hydration heat ratio is basically calculated by integrating the chemical compositions of both cement and binder and the basic formulas are as follows:

$$
\begin{gathered}
H=C \times H_{C} \\
H_{C}=p_{C_{3} S} H_{C_{3} S}+p_{C_{2} S} H_{C_{2} S}+p_{S G} H_{S G} \\
+p_{F A} H_{F A}+p_{C_{3} A}\left(H_{C_{3} A E T}+H_{C_{3} A}\right) \\
+p_{C_{4} A F}\left(H_{C_{4} A F E T}+H_{C_{4} A F}\right) \\
=\sum p_{i} \times H_{i}
\end{gathered}
$$


of MIP test and the assumptions applied to model foundation cannot be applied to the real phenomenon. However, the model developed in this study purposes to be used to the establishment of description and the soundness evaluation system in terms of composite micro-structure of concrete rather than to estimate exactly the void structure, so it is found that if it can show a certain correlation, it can meet its development goal.
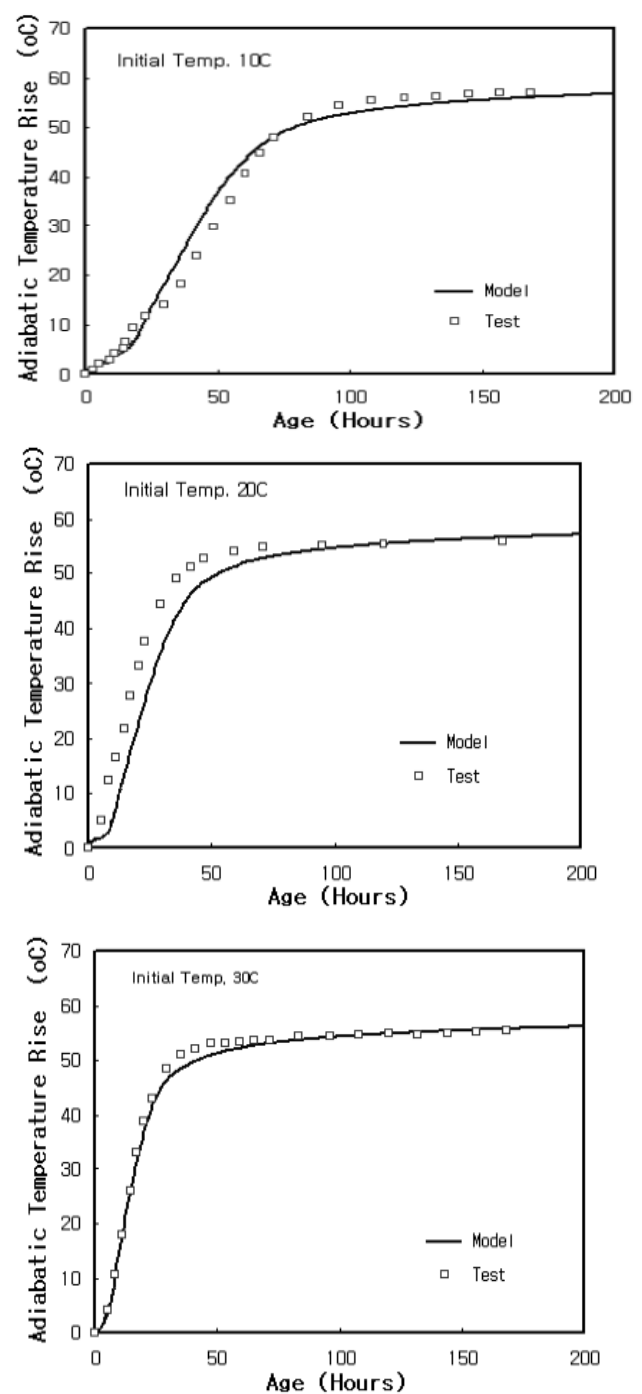

Fig. 6. Comparison of model to estimate hydration heat to the test results

\section{CONCLUSION}

This study analyzed the change of micro-structure caused by freeze thaw and sulfate-including corrosion out of the factors to deteriorate nuclear power structures. When it comes to the freeze thaw, the change of mass and elastodynamics coefficient until 150 cycles and the change of void at the point of 50 cycles were measured and when it comes to the sulfate-including corrosion, the change of length and mass and the hydrates were done.

In addition, this study developed a program to estimate the revelation of micro-texture structure caused by the concrete hydration reaction and compared and reviewed it to test results. Currently, the model formulas applied to the program are examined and improved for more exact estimation and it's thought that the developed program can be used to the models to estimate the strength and durability of concrete in future.

\section{ACKNOWLEDGMENT}

This work was supported by the Nuclear Research \& Development of the Korea Institute of Energy Technology Evaluation and Planning (KETEP) grant funded by the Korea government Ministry of Knowledge Economy. (No. 2011T100200161)

\section{REFERENCES}

[1] P. A. M. Basheer, S. E. Chidiact, and A. E. Long, "Predictive models for deterioration of concrete structures," Construction and Building Materials, vol. 10, no. 1, pp. 27-37, 1996

[2] M. S. Cheung and B. R. Kyle, "Service life prediction of concrete structures by reliability analysis," Construction and Building Materials, vol. 10, no. 1, pp. 45-55, 1996

[3] P. Schiessl, "Durability of reinforced concrete structures," Construction and Building Materials, vol. 10, no. 5, pp. 289-292, 1996.

[4] L. O. Nilsson, "Interaction between microclimate and concrete - a prerequisite for deterioration," Construction and Building Materials, vol. 10 , no. 5 , pp. 301-308, 1996

[5] C. Andrade and C. Alonso, "Corrosion rate monitoring in the laboratory and on-site," Construction and Building Materials, vol. 10, no. 5, pp. 315-328, 1996

[6] M. Raupach, "Chloride-induced macrocell corrosion of steel in concrete-theoretical background and practical consequences," Construction and Building Materials, vol. 10, no. 5, pp. 329-338, 1996.

[7] J. Mietz and B. Isecke, "Monitoring of concrete structures with respect to rebar corrosion," Construction and Building Materials, vol. 10, no. 5, pp. 367-373, 1996

[8] D. W. S. Ho and G. J. Chirgwint, "A performance specification for durable concrete," Construction and Building Materials, vol. 10, no. 5, pp. 375-379, 1996

[9] F. Hunkeler, "The resistivity of pore water solution-a decisive parameter of rebar corrosion and repair methods," Construction and Building Materials, vol. 10, no. 5, pp. 381-389, 1996

[10] T. Nireki, "Service life design," Construction and Building Materials, vol. 10 , no. 5, pp. 403-406, 1996

[11] H. Saricimen, M. Maslehuddin, A. lob and O.A. Eidt, "Evaluation of a surface coating in retarding reinforcement corrosion," Construction and Building Materials, vol. 10, no. 7, pp. 507-513, 1996

[12] S. Ahmad, B. Bhattacharjee, and R. Wason, "Experimental Service Life Prediction of Rebar-Corroded Reinforced Concrete Structure," ACI Materials Journal / July-August 1997

[13] P. Castro, L. Veleva and M. Balancan, "Corrosion of reinforced concrete in a tropical marine environment and in accelerated tests," Construction and Building Materials, vol. 11, no. 2, pp. 75-81, 1997

[14] J. Gulikers "Development of a galvanic monitoring probe to improve service life prediction of reinforced concrete structures with respect to reinforcement corrosion," Delft University of Technology, The Netherlands, Construction and Building Materials, vol. 11, no. 3, pp. 143-148, 1997

[15] M. Raupach, P. Schiessl, B. S. Aachen, S. Schiessl, and F. R. Aachen, "Monitoring system for the penetration of chlorides, carbonation and the corrosion risk for the reinforcement," Germany, Institute for Building Materials Research, Aachen, Germany, Construction and Building Materials, vol. 11, no. 4, pp. 207-214, 1997

[16] H. Saadatmanesh "Extending service life of concrete and masonry structures with fiber composites," University of Arizona, Tucson, Arizona, USA, Construction and Building Materials, vol. 11, no. 5-6, pp. 327-335, 1997

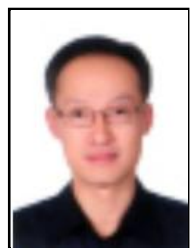

Jong-Suk Lee is a senior researcher in Structural Engineering Research Division, Korea Institute of Construction Technology(KICT), Republic of Korea. He received his BSc, MSc and $\mathrm{PhD}$ in Hanyang University, Republic of Korea. His research concerns the durability of NPP(Nuclear Power Plant) concrete structures, structural analysis of concrete structure. 
Ho-Jae Lee is a researcher in Structural Research Division, Korea Institute of Construction Technology(KICT), Republic of Korea. He received his BSc in Suwon University, Republic of Korea, MSc in Yonsei University, Republic of Korea. His research interest covers cement chemistry, corrosion of steel in concrete and its quantitative evaluation.

Myungsug Cho is a research fellow in the Plant Construction \& Engineering Laboratory, KHNP Central Research Institute, Korea Hydro \& Nuclear Power Co., LTD, South Korea. His research interest covers high performance concrete development and seismic engineering of Nuclear Power Plant structures.

Do Gyeum Kim is a research fellow in Structural Engineering Research Division, Korea Institute of Construction Technology(KICT), Republic of Korea. He received his BSc, MSc and $\mathrm{PhD}$ in Chungnam National University, Republic of Korea. His research concerns the durability of concrete structures in terms of corrosion of steel in concrete, ionic transport and microstructure analysis of concrete. 